\title{
LAS ÁREAS DE MONTAÑA EN CANTABRIA ANTE EL RETO DE SU DESARROLLO SOSTENIBLE
}

\author{
Carmen DELGADO VIÑAS \\ Departamento de Geografía, Urbanismo y Ordenación del Territorio, Universi- \\ dad de Cantabria
}

Recibido: $13 / 04 / 2010$

Aceptado: $22 / 04 / 2010$

RESUMEN: El objetivo fundamental de la Ley 45/2007 de Desarrollo Sostenible del Medio Rural, como su propio título sugiere, es el progreso de los espacios rurales entendido bajo una nueva perspectiva territorial ${ }^{2}$. En consecuencia, superando el enfoque antagónico tradicional entre el campo y la ciudad, la Ley española toma como punto de partida la consideración de la diversidad actual de los espacios rurales al afirmar que no existe un medio rural único, sino medios rurales múltiples y diferentes con necesidades de atención distintas.

El paso previo para la aplicación de la Ley ha sido la delimitación de los diferentes tipos de áreas o "zonas" rurales existentes en cada Comunidad Autónoma con el fin de disponer de fórmulas de apoyo específicas, en función de las necesidades particulares de cada territorio y en razón de la situación provocada por las principales tendencias de la dinámica territorial reciente: la diversificación económica, la desagrarización y la despoblación. Las dos primeras pueden considerarse como rasgos comunes a todos los espacios rurales, la tercera como una seña diferencial que afecta en particular a las áreas más desfavorecidas.

$\boldsymbol{P A L A B R} \boldsymbol{A S} \boldsymbol{C L} \boldsymbol{A V E}$ : Áreas de montaña, espacio rural, Ley de desarrollo sostenible, Cantabria, Zonas a revitalizar.

\footnotetext{
${ }^{1}$ Este artículo se enmarca en el Proyecto de Investigación SEJ2007-67655-C05-03 (Plan Nacional I+D+i 2007-2010) en el que está trabajando actualmente un grupo de investigadores de las Universidades de Cantabria, Oviedo y el País Vasco y del que la autora es Investigadora Principal. Asimismo, recoge algunos resultados del diagnóstico territorial realizado por la autora, por encargo de la Consejería de Desarrollo Rural del Gobierno de Cantabria, para la aplicación de la Ley 45/2007 de Desarrollo Sostenible del Medio Rural.

2 (Ley 45/2007 de 13 de diciembre de 2007, BOE 299, pp. 51339-51349). Como manifiesta de forma explícita en su Preámbulo I: "Es una Ley de orientación territorial, lo que implica que será aplicada tomando en consideración criterios y directrices de ordenación territorial. Singularmente la Ley contempla zonas rurales diferenciadas según una tipología establecida, define zonas rurales prioritarias y prevé el establecimiento de un plan por zona rural. Las acciones y medidas previstas en la Ley son multisectoriales y medioambientales. Coherentemente reflejan la nueva realidad de un medio rural económicamente cada vez más diversificado y al que se le reconoce una importante multifuncionalidad para la sociedad en su conjunto" (los subrayados son míos).
} 
MOUNTAIN AREAS IN CANTABRIA FACE THE CHALLENGE OF THEIR SUSTAINABLE DEVELOPMENT

ABSTRACT: The main objective of the Law 45/2007 of Sustainable Rural Development, as its own title suggests, is the progress of rural areas understood under a new territorial perspective. Consequently, surpassing the traditional antagonistic approach between the countryside and the town, the Spanish law takes like departure point the consideration of the present diversity from the rural spaces when affirming that unique rural means does not exist, but many different rural areas with different needs of attention.

The previous step for the implementation of the Law has been the delineation of the different types of rural areas or "zones" in each Autonomous Community with the purpose to provide specific support methods, depending on the particular needs of each territory in regard to the situation caused by the main trends of recent territorial dynamics: economic diversification, disagrarianization and depopulation. The first two can be considered like common characteristics to all the rural spaces, the third like a differential sign that particularly affects to the most disadvantaged areas.

KEY WORDS: Mountain areas, Rural space, Law of sustainable development, Cantabrian Region, Areas to revitalize.

\section{LES ZONES DE MONTAGNE DANS LA CANTABRIE EN FACE DU DÉFI DE LEUR DÉVELOPPEMENT DURABLE}

RÉSUMÉ: L'objectif fondamental de la Loi 45/2007 de Développement Durable du Milieu Rural, comme son propre titre suggère, c'est le progrès des espaces ruraux compris sous une nouvelle perspective territoriale. Par conséquent, en dépassant l'analyse antagonique traditionnelle entre le champ et la ville, la Loi espagnole prise comme point de départ la considération la considération de la diversité actuelle des espaces ruraux en affirmant qu'il n'existe pas un moyen rural unique, mais des moyens ruraux multiples et différents avec des nécessités d'attention différentes.

Le pas préalable pour l'application de la Loi a été la délimitation des différents types d'aires ou de "zones" rurales existantes dans chaque Communauté Autonome pour disposer des formules spécifiques d'appui, en fonction des nécessités particulières de chaque territoire et en raison de la situation provoquée par les principales tendances de la dynamique territoriale récente: la diversification économique, la desagrairization et le dépeuplement. Les deux premières peuvent être considérées comme des traits communs à tous les espaces ruraux, la troisième comme un signe différentiel qui touche en particulier les aires les plus défavoriseés.

MOTS-CLÉS: Zones de montagne, Espace rural, Loi de développement durable, Région Cantabrique, Zones à revitaliser.

\section{AS ÁREAS DAS MONTANHAS DE CANTABRIA DESDE O DESAFIO DO SEU DESENVOLVIMENTO SUSTENTÁVEL}

RESUMO: O objetivo principal da lei 45/2007 de Desarrollo Sostenible del Medio Rural, como seu próprio título sugere, é o progresso dos espaços rurais compreendidos sob uma perspetiva territorial nova. Consequentemente, superando o antagonismo tradicional entre o campo e a cidade, a lei espanhola parte como o ponto da partida a consideração da diversidade atual dos espaços rurais ao afirmar que os meios rurais originais não existem, e sim meios rurais múltiples e diferentes com outro tipo de necessidades de atenção.

A etapa precedente para a aplicação da lei foi o limite dos tipos diferentes das áreas ou das "zonas" rurais existentes em cada Comunidad Autónoma com a finalidade de ter as fórmulas específicas da sustentação, baseadas nas necessidades particulares de cada território e com respeito à situação causada pelas tendências principais da dinâmica territorial recente: a diversificação econômica, a desagrarización e a despovoação. As duas primeiras podem ser consideradas como 
características comuns a todos os espaços rurais, a terceira como um diferencial do sinal que afeta particularmente às áreas mais desfavorecidas.

PALAVRAS CHAVE: Áreas de montanha, espaço rural, Lei de desenvolvimento sustentável, Cantabria, Zonas a reavivar.

\section{LA DIFERENCIACIÓN DE ZONAS RURALES EN CANTABRIA A EFECTOS DE LA APLICACIÓN DE LA LEY 45/2007}

Para iniciar la identificación y el deslinde del medio rural de Cantabria, de acuerdo con los criterios básicos establecidos en la Ley 45/2007, se han considerado como espacios rurales los ámbitos territoriales integrados por los municipios que tienen una población menor de 30.000 habitantes y una densidad inferior a $100 \mathrm{hab} / \mathrm{km}^{2}$. En 2008 estas dos condiciones las reunían 71 municipios de los 102 que tiene la Comunidad Autónoma $(69,6 \%)$, con una superficie total de $4.385,96 \mathrm{~km}^{2}$ (83,5\% de la región) y 92.533 habitantes $(15,9 \%$ del total regional).

Tabla 1. Rasgos generales del medio rural de Cantabria

\begin{tabular}{lrrrrr}
\hline \multicolumn{1}{c}{ Indicadores } & $A$ & $B$ & $C$ & $D$ & $E$ \\
\hline Superficie $\left(\mathrm{km}^{2}\right)$ & $5.252,59$ & $4.385,96$ & 83,50 & $4.613,58$ & 87,83 \\
Población 2008 & 582.138 & 92.533 & 15,90 & 122.957 & 21,12 \\
Densidad (hab/km²) & 110,83 & 21,10 & 19,04 & 26,65 & 24,05 \\
Renta per cápita en 2004 (€) & 12.339 & 9.627 & 78,02 & 9.995 & 81,00 \\
Pob. mayor de 65 años (\%) & 18,43 & 26,39 & 143,17 & 25,59 & 138,85 \\
Afiliados a la Seg.Social Agraria & 4,15 & 16,38 & 394,88 & 14,29 & 344,48 \\
Empleos agrarios (\%) & 3,99 & 21,22 & 531,80 & 18,27 & 457,91 \\
Población dispersa (\%) & 17,83 & 62,07 & 348,21 & 56,61 & 317,54 \\
Evolución de la población 1970-2001 & 14,56 & $-24,20$ & $-166,25$ & $-17,87$ & $-122,74$ \\
Evolución de la población 1999-2008 & 10,15 & 4,40 & 43,32 & 6,34 & 62,46 \\
Superficie municipal de uso urbano (\%) & 5,64 & 4,08 & 72,35 & 4,92 & 87,23 \\
\hline A, Coln
\end{tabular}

A, Comunidad Autónoma de Cantabria; B, Municipios netamente rurales (71); C,\% sobre total de Cantabria; D, Municipios rurales (80); E, \% sobre total de Cantabria

Estos 71 municipios constituyen el grueso de los que tienen un carácter indiscutiblemente rural. Sin embargo, algunos otros poseen también rasgos más netamente rurales que urbanos, por lo que parece conveniente añadirlos al grupo de los calificados como rurales, una situación que contempla de manera explícita la normativa. Es el caso de los términos municipales que tienen menos de 5.000 habitantes y una densidad de población inferior a $200 \mathrm{hab} / \mathrm{km}^{2}$, como sucede en Potes, San Vicente de la Barquera, Comillas, Santillana del Mar, Miengo, Villaescusa, Ribamontán al Mar, Limpias y Ampuero; nueve términos municipales que, sumados a los anteriores, arrojan un total de 80 municipios rurales o semirurales con una extensión de $4.613,58 \mathrm{~km}^{2}(87,83 \%$ del territorio regional) sobre los que viven 122.957 personas (21,12\% de la población total) en 2008. 
Aunque no puedan considerarse como estrictamente rurales, aplicando con rigor tajante los criterios e indicadores reglados, es imprescindible incluir en el medio rural a varios municipios más atendiendo a distintos motivos fundamentados y contemplados, asimismo, en la normativa manejada.

Es el caso del término municipal de Cabezón de la Sal, que desde hace varios siglos es el núcleo de referencia de la mayor parte del área de cabecera de los ríos Saja y Nansa, correspondiente a las comarcas históricas de Cabuérniga y Tudanca, y aún hoy continúa ejerciendo las funciones de centro comarcal de servicios de nivel subregional para un amplio territorio rural que, además, coincide parcialmente con una comarca-programa Leader I, II y Plus.

Idéntica razón funcional aconseja incluir en el medio rural al municipio de Los Corrales de Buelna cuyo núcleo principal ha funcionado como centro comarcal articulador, junto con Reinosa, de todo el área del corredor del Besaya, identificado con la comarca tradicional de Iguña y el área septentrional de la comarca de Campoo. Dicho territorio se corresponde parcialmente en la actualidad con otra comarca programa Leader.

Los motivos aducidos en el caso anterior se repiten, en mayor medida aún si cabe, en el de Reinosa, un núcleo con carácter urbano en torno al que gira la dinámica socioeconómica y territorial de la comarca de Campoo-Los Valles, equiparada parcialmente con la histórica Merindad de Campoo.

Igualmente parece conveniente integrar en sus zonas respectivas los términos municipales de Marina de Cudeyo, Medio Cudeyo, Reocín, Santa María de Cayón y Suances por razones de coherencia territorial, al estar plenamente integrados y articulados en el contexto territorial de los municipios netamente rurales que les rodean. Por tales causas se aconseja incluir dichos municipios en el medio rural, al que pertenecen inequívocamente, como espacios que están experimentando intensos procesos de rururbanización, aunque por ese mismo motivo, deben clasificarse como municipios rurales periurbanos.

Como resultado de estas consideraciones, sólo quedarían definitivamente excluidos del medio rural, y por tanto de la aplicación directa de las medidas previstas en la citada Ley 45/2007 para el período de programación 2010-2014, 14 municipios comprendidos en dos áreas urbanas claramente definidas:

El eje Santander-Torrelavega, en el que aparte de estos dos municipios se incluyen El Astillero, Camargo, Piélagos, Santa Cruz de Bezana, Polanco y Cartes.

$\checkmark$ La mayor parte de la franja litoral oriental de Cantabria con Castro Urdiales, Laredo, Colindres, Argoños, Noja y la propia Santoña. 
El medio rural cántabro delimitado a efectos de la aplicación de la Ley 45/2007 abarca 88 municipios, tiene una extensión de 4.856,67 $\mathrm{km}^{2}$ (el 92,46\% de la superficie regional), 189.825 habitantes (el $32,61 \%$ del total) y una densidad de población media de 39,09 habitantes por $\mathrm{km}^{2}$.

Tomando como referencia los valores medios del conjunto de los municipios cántabros clasificados como rurales en primera instancia, se han estimado diferentes grados de ruralidad según el número de valores superiores o inferiores a la media regional que presenta cada término municipal. Tras la aplicación de esos indicadores se han agrupado los 80 municipios rurales, como establece la Ley, en tres tipos o zonas clasificadas como a revitalizar, intermedia y periurbana.

El territorio clasificado como zona a revitalizar abarca 34 municipios, 29 de los cuales reúnen todas las condiciones requeridas al estar por debajo de la media regional en los valores relativos a la densidad de población y la renta per cápita y por encima de la media en cuanto al porcentaje de población activa agraria, el tiempo de desplazamiento a la ciudad más próxima, el peso de la población dispersa y/o la pendiente media. En los otros 5 no se da alguna de esas condiciones, pero todos ellos tienen un índice de envejecimiento y/o unas tasas de regresión de su población superiores a la media rural de la región. El ámbito considerado como zona periurbana está formada por 20 términos municipales la totalidad de los cuales cumple simultáneamente todas las condiciones requeridas en cuanto a estar por encima de los valores medios de densidad de población y renta per cápita, y por debajo de ellos en porcentaje de población activa agraria y tiempo de desplazamiento a la ciudad más próxima. Los restantes 26 municipios rurales que se encuentran entre ambas situaciones forman el territorio identificado como zona intermedia.

Tabla 2. Principales caracteres de las zonas en que se clasifican los municipios de Cantabria para la aplicación de la Ley 45/2007

\begin{tabular}{|c|c|c|c|c|}
\hline \multirow{2}{*}{ Indicadores } & \multicolumn{3}{|c|}{ Municipios rurales } & \multirow{2}{*}{$D$} \\
\hline & $A$ & $B$ & $C$ & \\
\hline Número de municipios & 34 & 26 & 20 & 22 \\
\hline Superficie $\left(\mathrm{km}^{2}\right)$ & $2.842,69$ & $1.092,12$ & 678,77 & 639,00 \\
\hline Población en 2008 (hab.) & 24.662 & 45.502 & 52.793 & 459.181 \\
\hline Densidad (hab. $/ \mathrm{Km}^{2}$ ) & 8,68 & 41,66 & 77,78 & 718,59 \\
\hline Empleos agrarios (\%) & 37,90 & 17,88 & 11,61 & 1,53 \\
\hline Renta per capita en $2004(€)$ & 8.002 & 9.766 & 10.903 & 12.096 \\
\hline Variación anual de la población 1999-2008 (\%) & $-0,96$ & 0,22 & 2,22 & 1,25 \\
\hline Población mayor de 65 años (\%) & 30,86 & 23,45 & 19,33 & 15,66 \\
\hline Población dispersa (\%) & 68,37 & 50,55 & 54,27 & 25,57 \\
\hline
\end{tabular}

Las diferencias entre unos y otros tipos de espacios rurales son muy acusadas y elocuentes, comenzando por la intensidad humana de ocupación y uso del te- 
rritorio. El ámbito territorial constituido por los municipios a revitalizar es mucho mayor que los otros dos, incluso que la suma de ambos; no obstante el volumen de población que allí habita es mucho más reducido. Los valores medios de la densidad de población ponen de relieve estos hechos de forma palmaria: en la zona a revitalizar el número de habitantes por kilómetro cuadrado no llega a 9 mientras que en la zona intermedia se aproxima a 42 y en la periurbana es casi 78.

Idénticos contrastes se perciben al observar la estructura ocupacional de la población. Mientras que en la zona a revitalizar los empleos agrarios representan casi el 38\% del empleo total, en la zona intermedia se reducen a menos de la quinta parte y en la periurbana apenas representan poco más del 11\%.

La tasa de envejecimiento (población mayor de 65 años/población total*100), en un contexto de valores muy altos, es bastante más elevado en los municipios de la zona a revitalizar $(30,86 \%)$ que en la intermedia y la periurbana $(23,45 \%$ y $19,33 \%$ respectivamente).

La tasa de dispersión (población que habita fuera del núcleo principal/población total*100) y la distancia en tiempo a los núcleos urbanos de servicios más grandes de la región, aspectos que significan condiciones muy diferentes en cuanto a la accesibilidad, son también indicadores que reflejan la desventaja comparativa de los municipios de la zona a revitalizar.

No puede extrañar, por tanto, que existan notables desigualdades en cuanto a la renta per cápita media; si los habitantes de la zona periurbana e intermedia disponían en 2004 de unos ingresos medios teóricos próximos a $11.000 €$, los de la zona a revitalizar apenas rebasaban $\operatorname{los} 8.000 €$.

Este conjunto de desventajas socioeconómicas pueden explicar con bastante nitidez la evolución reciente de la población de las distintas zonas del medio rural cántabro.

La zona a revitalizar corresponde a un ámbito espacial que sufrió una verdadera sangría humana hasta finales del siglo XX. Sólo en los treinta años transcurridos entre 1970 y 2001 este espacio perdió, en conjunto, algo más de un $39 \%$ de sus habitantes. Pero, además, el menoscabo demográfico no ha terminado: de 1999 a 2008, en un contexto general de crecimiento, este territorio ha seguido perdiendo casi otro $9 \%$ de sus habitantes, a un ritmo anual de $-0,96 \%$.

Frente a esta situación de largo y continuado proceso de despoblación, las otras zonas rurales han tenido una dinámica demográfica bastante diferente. 
Los municipios de la zona intermedia perdieron también población en las últimas décadas del siglo XX (-15,33\%), pero el éxodo parece haberse contenido en los primeros años de la centuria actual, que son testigos de una leve, pero significativa, recuperación ya que su población ha crecido, en conjunto, 2, \% en los nueve años transcurridos entre 1999 y 2008.

El área rural periurbana tuvo mermas de población poco importantes en el tercio final del siglo XX $(-1,01 \%)$ pero, además, ha experimentado un crecimiento poblacional muy acusado en la actual centuria ya que su contingente poblacional ha aumentado casi un $20 \%$ de 1999 a 2008, lo que parece indicar el inicio de una clara inversión de la tendencia demográfica característica de los espacios rurales durante la segunda mitad del siglo pasado.

Desde una perspectiva cuantitativa las diferencias entre los distintos niveles de ruralidad en se puede clasificar el medio rural cántabro se presentan con una claridad meridiana; no ocurre así en lo que se refiere a la distribución territorial propiamente dicha.

A grandes rasgos, la zona a revitalizar está constituida por municipios que presentan una notable contigüidad territorial. Con la salvedad de algún municipio lebaniego y algunos otros situados a lo largo del eje que une Iguña y Campoo, aquélla dibuja perfectamente la orla montañosa meridional de la región formando dos grandes conjuntos: uno occidental, más ancho en sentido latitudinal, que se identifica grosso modo con las comarcas históricas de Liébana y Cabuérniga-Tudanca. Otro oriental, más estrecho y alargado longitudinalmente, correspondiente a las comarcas de Campoo-Los Valles y de los Montes de Pas, entendidas ambas en un sentido amplio.

Ambas áreas más deprimidas quedan parcialmente separadas por una franja de términos municipales que, en dirección nordeste-suroeste, se extienden desde el valle medio del Pas hasta Valdeolea y que forman parte ya de la zona intermedia. Una zona que, en realidad, carece de continuidad y, por ende, de entidad territorial puesto que está integrada por municipios físicamente separados entre sí y repartidos por todo el territorio regional. Se encuentran situados, en unos casos, en áreas de montaña (en Liébana y Campoo-Iguña), salpicados en la franja litoral septentrional, de oeste a este, $y$, sobre todo formando una pequeña agrupación en el valle medio del Pas-Pisueña.

Los municipios clasificados como periurbanos, a pesar de que no componen propiamente un ámbito territorial continuo, se ubican en mayor medida en la franja litoral, en particular en el sector oriental donde tienen mayor presencia y contigüidad hasta llegar casi a constituir un espacio geográfico relativamente homogéneo en torno a los cursos bajos de los ríos Miera, Asón y Agüera. 
Figura 1. Clasificación de los municipios cántabros en tipos según niveles de ruralidad.

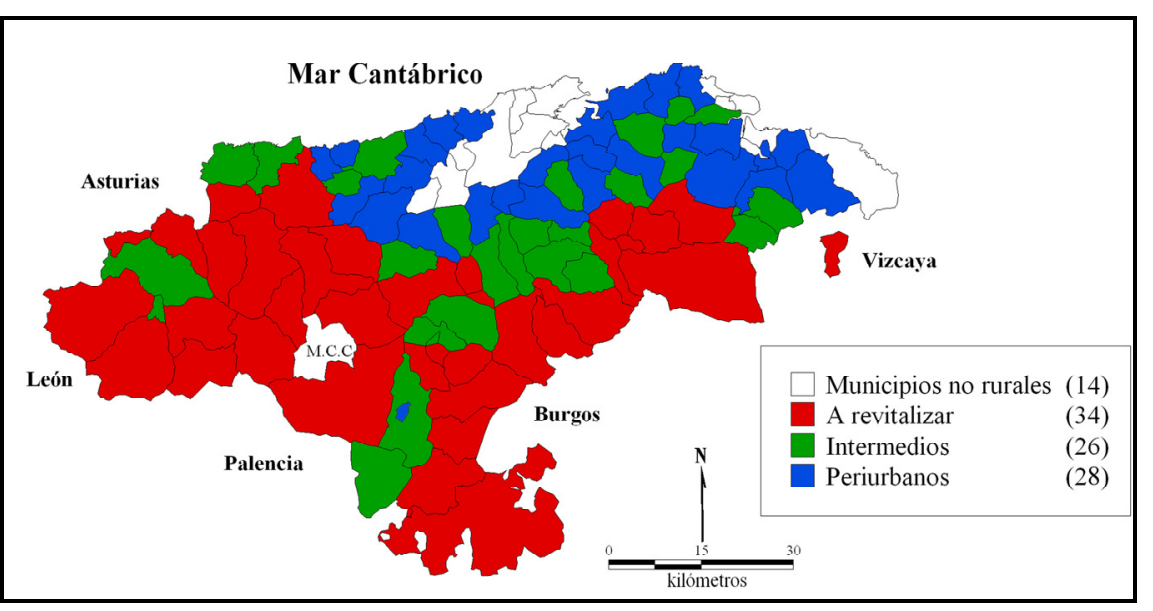

A partir de la clasificación de los municipios en grandes tipologías, se han podido considerar con mayor detalle y precisión las peculiaridades territoriales y socioeconómicas del medio rural de la región, que emanan del análisis de los indicadores requeridos oficialmente pero también de otros datos cuantitativos y cualitativos manejados y del conocimiento real del medio.

El objetivo buscado ha sido delimitar zonas homogéneas en la medida de lo posible a fin de facilitar la elaboración y aplicación de los planes de zona en un futuro próximo. Por ese motivo, salvo excepciones que se justifican más adelante, se ha procurado no integrar en la misma zona municipios con caracteres muy discordantes (periurbanos y a revitalizar, por ejemplo). Por el contrario, el criterio rector ha sido constituir y clasificar las diferentes zonas a partir del tipo predominante de municipios, aunque, al aplicarlo con flexibilidad, en dichas zonas haya que integrar obligatoriamente algunos términos municipales clasificados en otra categoría inmediata, inferior o superior.

La primera consecuencia de la utilización de este criterio-guía ha sido la constatación de la inexistencia territorial de una zona intermedia propiamente dicha. Como se apuntó antes, los municipios clasificados como intermedios, tras aplicar los indicadores requeridos, son menos numerosos que los clasificados en los otros tipos. Además, no forman un ámbito territorial continuo salvo en el área de la cuenca media del Pas-Pisueña donde se agrupan de forma adyacente 6 municipios de tipo intermedio (Corvera y Santiurde de Toranzo, Villafufre, Saro, Villacarriedo y Selaya) que suman poco más de $224 \mathrm{~km}^{2}$ y cuya población apenas rebasa los 9.000 habitantes. Esas dimensiones dan a esta área una "masa crítica" insuficiente para formar por sí misma una zona intermedia eficiente con 
vistas a su desarrollo sostenible. Razón por la cual, junto a otros motivos de coherencia territorial y funcional que se expondrán más adelante, ha parecido aconsejable integrar dichos municipios en el área espacial más amplia a la que han estado vinculados durantes siglos y con la que siguen articulados en el presente.

En consecuencia, en las zonas a revitalizar quedan integrados los municipios de carácter intermedio que están intercalados entre los términos municipales de aquella categoría, o que son colindantes con ellos, siempre que hayan tenido históricamente y sigan teniendo en la actualidad vínculos culturales o funcionales con el conjunto del ámbito territorial.

De igual forma, las zonas periurbanas están integradas mayoritariamente por municipios periurbanos y los términos municipales intermedios, intercalados e inmediatos, vinculados en el pasado y en el presente a aquéllos por medio de diversas formas de articulación.

El entendimiento teórico del funcionamiento de los espacios rurales, en general, y el conocimiento empírico del medio rural cántabro analizado, en particular, permiten afirmar con rotundidad que la combinación en la misma zona de municipios de diferente tipo, siempre que no sean muy dispares, lejos de romper la homogeneidad necesaria, refuerza la dinámica del conjunto y estimula las sinergias imprescindibles para lograr un desarrollo territorial más equilibrado $y$, en consecuencia, más sostenible.

Figura 2. Delimitación de zonas para la aplicación en Cantabria de la Ley 45/2007.

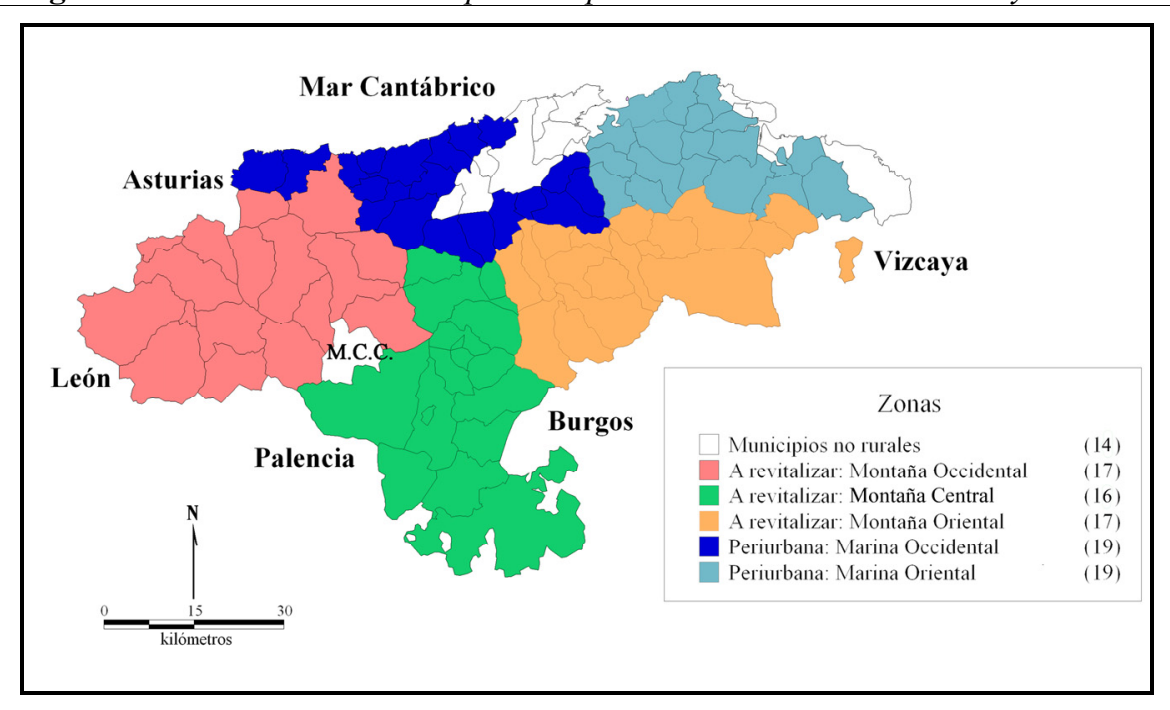


Tabla 3. Rasgos generales básicos de las zonas rurales delimitadas en la Comunidad Autónoma de Cantabria: zonas a revitalizar

\begin{tabular}{|c|c|c|c|}
\hline Tipo de zona & \multicolumn{3}{|c|}{ Zonas a revitalizar } \\
\hline Indicadores & $A$ & C & $D$ \\
\hline $\mathrm{N}^{\mathrm{o}}$ de municipios & 17 & 17 & 50 \\
\hline Superficie $\left(\mathrm{km}^{2}\right)$ & $1.340,48$ & 973,55 & $3.579,51$ \\
\hline Población en 2008 (habitantes) & 13.759 & 19.208 & 58.550 \\
\hline Densidad en $2008\left(\mathrm{hab} / \mathrm{km}^{2}\right)$ & 10,26 & 19,73 & 16,74 \\
\hline Superficie en pendiente $(\%)$ & 43,94 & 34,51 & 34,87 \\
\hline Población $>65$ años & 30,32 & 26,47 & 29,1 \\
\hline Renta per cápita (€) en 2004 & 8.132 & 8.465 & 8.592 \\
\hline Empleos agrarios $(\%)$ & 35,78 & 46,24 & 37,82 \\
\hline Dist. a núcleos $>30.000$ hab. (') & 62 & 38 & 45,3 \\
\hline Población dispersa $(\%)$ & 64,19 & 62,95 & 60,93 \\
\hline Evol. de la población $1970-2001$ & $-35,98$ & $-29,39$ & $-33,76$ \\
\hline Evol. de la población 1999-2008 & $-2,23$ & $-6,38$ & $-6,77$ \\
\hline Suelo para usos urbanos $(\%)$ & 2,14 & 3,03 & 4,11 \\
\hline \multicolumn{4}{|c|}{ A, Montaña Occidental; $B$, Montaña Central; $C$, Montaña Oriental; $D$, Total. } \\
\hline Tipo de zona & \multicolumn{3}{|c|}{ Zonas periurbanas } \\
\hline Indicadores & $A$ & $B$ & $C$ \\
\hline $\mathrm{N}^{\mathrm{o}}$ de municipios & 19 & 19 & 38 \\
\hline Superficie $\left(\mathrm{km}^{2}\right)$ & 635,31 & 641,85 & $1.277,16$ \\
\hline Población en 2008 (habitantes) & 80.528 & 50.747 & 131.275 \\
\hline Densidad en $2008\left(\mathrm{hab} / \mathrm{km}^{2}\right)$ & 126,75 & 79,06 & 102,79 \\
\hline Superficie en pendiente $(\%)$ & 20,36 & 21,6 & 20,98 \\
\hline Población $>65$ años & 19,48 & 19,15 & 19,31 \\
\hline Renta per cápita (€) en 2004 & 10.599 & 10.851 & 10.725 \\
\hline Empleos agrarios $(\%)$ & 9,93 & 17,57 & 13,75 \\
\hline Dist. a núcleos $>30.000$ hab. (') & 17 & 21 & 19 \\
\hline Población dispersa $(\%)$ & 50,81 & 50,56 & 50,69 \\
\hline Evol. de la población 1970-2001 & 1,22 & $-1,17$ & 0,02 \\
\hline Evol. de la población $1999-2008$ & 12,38 & 21,14 & 16,76 \\
\hline Suelo para usos urbanos (\%) & 9,75 & 9,48 & 9,61 \\
\hline
\end{tabular}

A, Marina Occidental; B, Marina Oriental; C, Total

El resultado último de la delimitación es la distribución del medio rural de Cantabria en cinco zonas razonablemente uniformes entre sí en cuanto a sus características y bastante equilibradas en sus dimensiones, tanto en la superficie de su territorio como en su tamaño poblacional y en cuanto al número de municipios que las integran:

$\checkmark$ Zonas a revitalizar: "Montaña Occidental" (Liébana-Cabuérniga Tudanca), "Montaña Central" (Campoo-Iguña) y "Montaña Oriental" (PasPisueña, Miera y Asón-Agüera).

$\checkmark$ Zonas periurbanas: "Marina Occidental" y "Marina Oriental"-Trasmiera. 


\section{LAS “ZONAS A REVITALIZAR": LAS ÁREAS DE MONTAÑA}

\section{II.1. La "Montaña Occidental" (Liébana-Cabuérniga-Tudanca)}

La zona denominada "Montaña Oriental" constituye una de las áreas más homogéneas de las delimitadas a partir de la aplicación de los indicadores propuestos oficialmente. Está formada por 17 municipios correspondientes a las comarcas históricas de Liébana (7), Cabuérniga y Tudanca (10). Liébana, además, es una comarca natural y una comarca Leader desde los primeros momentos de funcionamiento de la Iniciativa. Prácticamente lo mismo puede afirmarse de las otras dos comarcas, coincidentes con la cuenca del río Nansa y la cuenca alta y media del Saja. Los municipios que las integran, junto con algunos otros (Cabezón de la Sal, Mazcuerras, San Vicente de la Barquera, Udías y Val de San Vicente), pertenecen a la comarca Leader Saja-Nansa también desde el origen del programa.

Figura 3. Delimitación y localización de la "Montaña Occidental" de Cantabria.

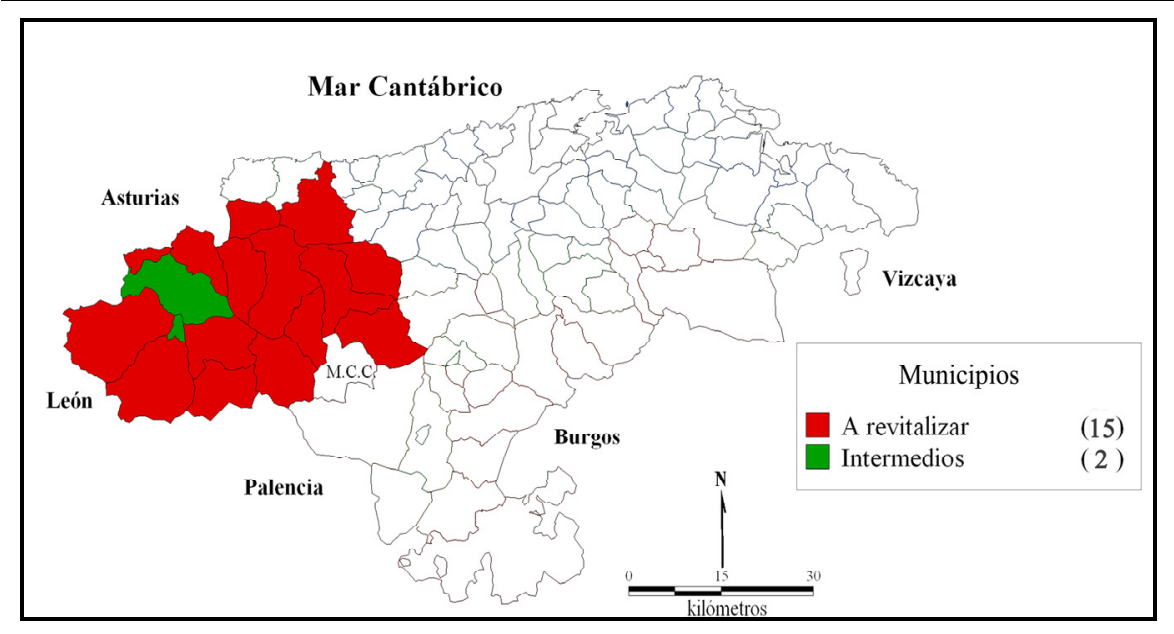

De los 17 municipios incluidos en la zona, 15 son clasificados como a revitalizar de acuerdo con los criterios normativos aplicables y sólo dos, Potes y Cillorigo de Liébana, son municipios de carácter intermedio según la valoración de los indicadores utilizados; no obstante, todos los criterios de delimitación territorial aplicables exigen su inclusión en el ámbito territorial de la zona a revitalizar. Por un lado, su localización en el centro geográfico de la comarca, completamente rodeados de municipios categóricamente necesitados de revitalización; si en alguna ocasión es ineludible el criterio de coherencia territorial es en ésta. 
Potes, además, ha sido y es el núcleo articulador de su comarca natural e histórica desde hace siglos. En la actualidad constituye un centro de servicios secundario para toda la comarca de Liébana de la que es centro de referencia indiscutible. Su funcionalidad como núcleo de centralidad comarcal queda fuera de toda duda así como su potencial papel dinamizador para el conjunto territorial en que se inscribe.

No obstante, en el siguiente análisis cuantitativo de la zona ha parecido conveniente hacer una doble elaboración de los datos, incluyendo y excluyendo Potes, para aprehender con mayor claridad las características del área y evitar las distorsiones que pudiera introducir la presencia de un municipio con algunos rasgos urbanos. Si bien, en este caso, por las reducidas dimensiones del municipio-cabecera, la diferencia entre unos y otros datos es casi insignificante.

El territorio de la "Montaña Occidental" posee una extensión de poco más de $1.300 \mathrm{~km}^{2}$, buena parte de la cual son tierras en pendiente, un hecho que expresa muy bien las condiciones orográficas de la mayoría de los municipios. Éstas alcanzan valores extremos en algunos municipios como Tresviso, cuyo territorio se aloja en el corazón del sistema montañoso mientras que los términos situados más cerca del litoral poseen mayor proporción de tierras llanas, como sucede en Herrerías y Valdáliga.

Figura 4. Distribución de la población en la "Montaña Occidental" de Cantabria.

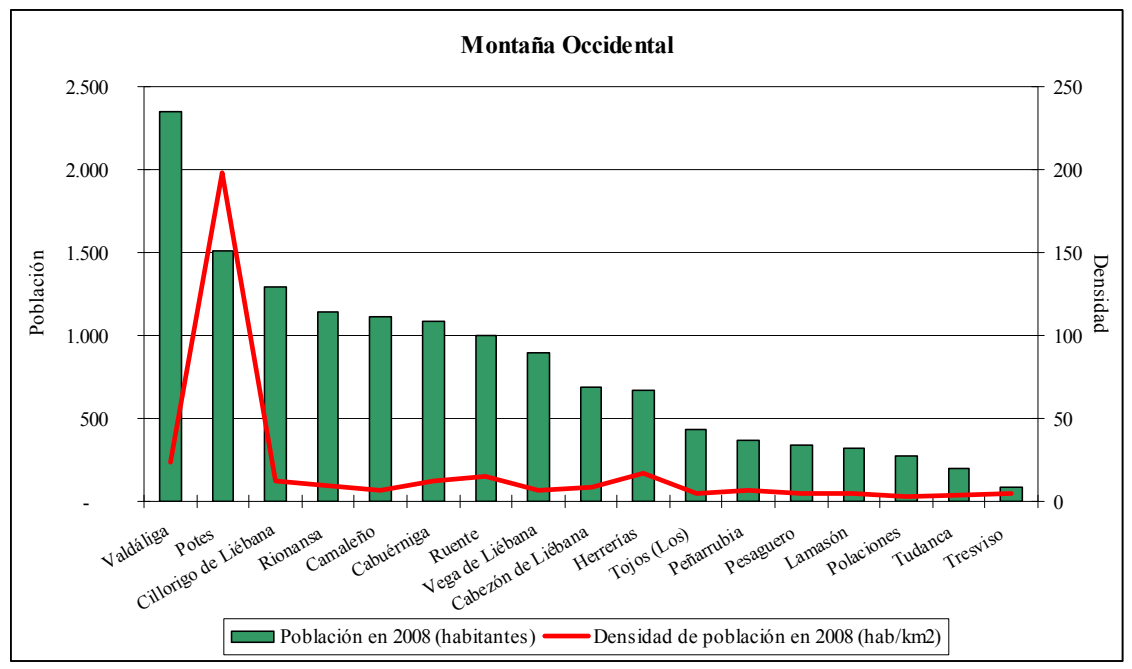

La población del conjunto comarcal no alcanza los 14.000 habitantes, una cifra que es el resultado de la suma de contingentes poblacionales minúsculos, como el de Tresviso ( 82 habitantes) y de otros de dimensiones medias en el 
contexto regional: los municipios de Cabuérniga, Camaleño, Cillorigo, Rionansa y Ruente tienen más de 1.000 habitantes y Valdáliga supera los 2.000. La capital lebaniega, con 1.511 habitantes en 2008, es una entidad de población significativa, más aún si consideramos la exigua superficie en que se concentra ese volumen poblacional $\left(7,64 \mathrm{Km}^{2}\right)$.

La relación entre extensión superficial y población, que da la medida de la intensidad de ocupación del territorio, arroja una densidad media muy baja, 9,19 $\mathrm{hab} / \mathrm{km}^{2}$; el valor aumenta un punto porcentual cuando se contabilizan los habitantes de Potes. También ese valor medio es suficientemente representativo ya que, si hacemos excepción de Potes $\left(197,77 \mathrm{hab} / \mathrm{km}^{2}\right)$ el resto de los municipios se sitúan en una horquilla comprendida entre los $3,03 \mathrm{hab} / \mathrm{km}^{2}$ de Polaciones y los $24,05 \mathrm{hab} / \mathrm{km}^{2}$ de Valdáliga. Las diferencias entre las comarcas incluidas en la zona no son significativas en este aspecto ya que la mayoría de los municipios (11 de 17) no llegan a los $10 \mathrm{hab} / \mathrm{km}^{2}$ que suele considerarse como el umbral de la despoblación.

El motivo de esta situación se encuentra en la evolución demográfica reciente, en las extraordinarias mermas de población que ha sufrido este ámbito territorial: en los últimos 30 años del siglo XX ha perdido más del $40 \%$ de la población que tenía en 1970 (-35,98\% si descontamos la de Potes). Pero, en esta ocasión, ese valor medio refleja situaciones bastante contrastadas entre algunos municipios que han tenido pérdidas aún mayores (Polaciones, -61,83\%, Tudanca, $-63 \%$ y Tresviso -70,79\%), otros con escasas disminuciones (Ruente, $-9,40 \%$ ) y algún otro que ha aumentado su población (Potes, 29,10\%).

Esta situación no parece tender a corregirse en el presente. En los primeros años del siglo XXI, y en un contexto de crecimiento demográfico incluso en muchos espacios rurales, la población de la zona ha seguido disminuyendo: mucho en algunos casos (Tudanca, Rionansa, Lamasón, Herrerías) y a un ritmo menor en otros. Sólo unos pocos términos han aumentado el volumen de su población; pero, aunque en ocasiones los porcentajes sean altos al referirse a un contingente de partida muy pequeño, los valores absolutos son también bastante reducidos (casos de Tresviso y Peñarrubia). Lo que resulta bastante elocuente es que la villa de Potes haya disminuido su población, a pesar de que lo haya hecho en proporciones reducidas.

No puede extrañar, en consecuencia, que la emigración de importantes contingentes de población, generalmente joven, haya redundado en la generación de altas tasas de envejecimiento: casi la tercera parte de los habitantes tienen más de 65 años y el valor medio (30,32\%) es superado en un significativo número de términos. Si la población más “joven” se encuentra en Potes $(21,38 \%$ de viejos) y Ruente (21,54\%), en Lamasón el índice de envejecimiento es 
$39,18 \%$ y en Pesaguero 39,24\%, valores que se encuentran entre los más elevados de la Comunidad Autónoma de Cantabria.

Se trata, además, de una población muy dispersa. La tasa media de dispersión se eleva a $64,19 \%$, y eso a pesar de que la concentración es máxima en Tresviso y Potes (la inclusión de este último rebaja el valor medio en 4 puntos porcentuales). Por el contrario, en la mayoría de los municipios más de la mitad de sus habitantes viven en núcleos distintos del principal, aldeas minúsculas casi siempre, llegando a superar el $75 \%$ en 8 términos. La ausencia de diferencias relevantes entre unas y otras comarcas de la zona permite afirmar que la dispersión es la pauta de poblamiento generalizada en un territorio que tiene las tasas de dispersión más altas de toda Cantabria.

Una importante proporción de esa escasa población envejecida se dedica a la actividad agraria, el 35,78\% (37,92\% si prescindimos de Potes donde sólo el $1,43 \%$ de sus habitantes son activos agrarios). La tasa es mucho más alta en algunos municipios (Lamasón, 82,09\%, Polaciones, 62,50\%) hasta el punto de que la actividad agraria puede ser considerada casi como la única base productiva en su territorio. Los porcentajes son menores, en general, en algunas áreas de Cabuérniga y en unos pocos municipios lebaniegos con especial peso de las actividades turísticas y de servicios.

El caso más llamativo es el de Potes, el término municipal que presenta la mayor tasa de población ocupada en el sector servicios de toda Cantabria, por encima, incluso, de la propia capital regional. Un hecho que no resulta extraño si se considera que la villa funciona como centro de referencia y cabecera comarcal para toda el área lebaniega. Esta situación no se produce de forma tan acusada en ningún núcleo de Cabuérniga puesto que la mayor parte del área tiene sus centros de servicios y núcleos de referencia fuera de la comarca, en las villas de San Vicente y Comillas y en la ciudad de Torrelavega, con las que tienen mejor conectividad.

Estos caracteres se explican, en gran medida, por las dificultades de accesibilidad de la mayor parte de este territorio. La distancia media, medida en tiempo, desde la zona a la ciudad mayor de 30.000 habitantes más próxima, en este caso Torrelavega, es de más de una hora. La situación de alejamiento y aislamiento, la mayor de toda Cantabria, es especialmente grave para algunos municipios: se tarda en torno a una hora y media o más en llegar desde Tresviso, Camaleño, Pesaguero, Polaciones y Vega de Liébana a Torrelavega, el núcleo más cercano para acceder a servicios algo más especializados que los básicos y cotidianos.

Los rasgos analizados, en su conjunto, pueden servir para explicar que la "Montaña Occidental" se encuentre entre las áreas cántabras con menores nive- 
les de renta. Frente a una renta per cápita regional que superaba los 12.000 euros en 2004, la media comarcal se situaba en el entorno de los 8.000 euros, levemente por encima si se incluyen los valores de Potes y mínimamente por debajo si se prescinden de ellos. Dos municipios, Lamasón y Peñarrubia, no llegaban a 7.000 euros y otros 7 (Herrerías, Pesaguero, Polaciones, Los Tojos, Tresviso, Tudanca y Vega de Liébana) tenían una renta per cápita entre 7.000 y 8.000 euros; en resumen, prácticamente la mitad de los municipios de la zona tenían rentas inferiores a la media. Sólo en Potes la renta per cápita superaba en esa fecha los 10.000 euros, aunque estaba aún muy lejos de la media regional.

Del análisis exhaustivo realizado se desprende, en consecuencia, la absoluta necesidad de aplicar con urgencia medidas para estimular el dinamismo socioeconómico de un territorio caracterizado por la uniformidad territorial en su situación de menor desarrollo en el contexto regional y estatal.

\section{II.2. La "Montaña Central" (Campoo-Iguña)}

En el sector central de la Cordillera Cantábrica en su tramo cántabro se emplazan dos comarcas históricas. Una de ellas corresponde a la parte septentrional de la antigua "Merindad de Campoo" o "Merindad de Aguilar de Campoo", la otra se identifica con el Valle de Iguña coincidente con la cuenca alta del río Besaya. La zona está constituida por 16 municipios de los que la mayoría (10), son municipios clasificados como a revitalizar de acuerdo con los criterios normativos aplicables, 5 (Bárcena de Pie de Concha, Campoo de Enmedio, Cieza, Molledo y Valdeolea) son municipios de carácter intermedio y 1 (Reinosa) es urbano según la valoración de los indicadores utilizados. La inclusión de este último, a pesar del criterio general utilizado que se expuso antes, queda suficientemente justificada a partir de los argumentos que se aportan más adelante.

Desde una perspectiva ecológica, la mayor parte de Campoo está situada en las tierras que constituyen la culminación de la Cordillera en el área que forma su divisoria de aguas, en un sector montañoso de mayor altitud pero de horizontes abiertos y predominio de áreas llanas. Por el contrario, la totalidad de Iguña y algunos municipios campurrianos (Pesquera, Santiurde de Reinosa, Hermandad de Campoo de Suso) se alojan en el arranque de la vertiente septentrional de la misma, en un sector de la montaña definido por el carácter abrupto y escarpado de su relieve, los contrastes altitudinales y topográficos y la primacía de las tierras en pendiente.

La pendiente media del conjunto de la zona es elevada, pero ese valor medio es el resultado de condiciones bastante dispares. Mientras que los municipios situados en el inicio de la vertiente septentrional, pertenezcan al Valle de Iguña o a Campoo, presentan valores muy altos, los ubicados sobre las tierras de la divi- 
soria y en el inicio de la vertiente meridional son más llanos. Si bien es cierto que, en este caso, el beneficio de la menor pendiente es contrarrestado por las desventajas naturales vinculadas a la mayor altitud.

Figura 5. Delimitación y localización de la "Montaña Central" de Cantabria.

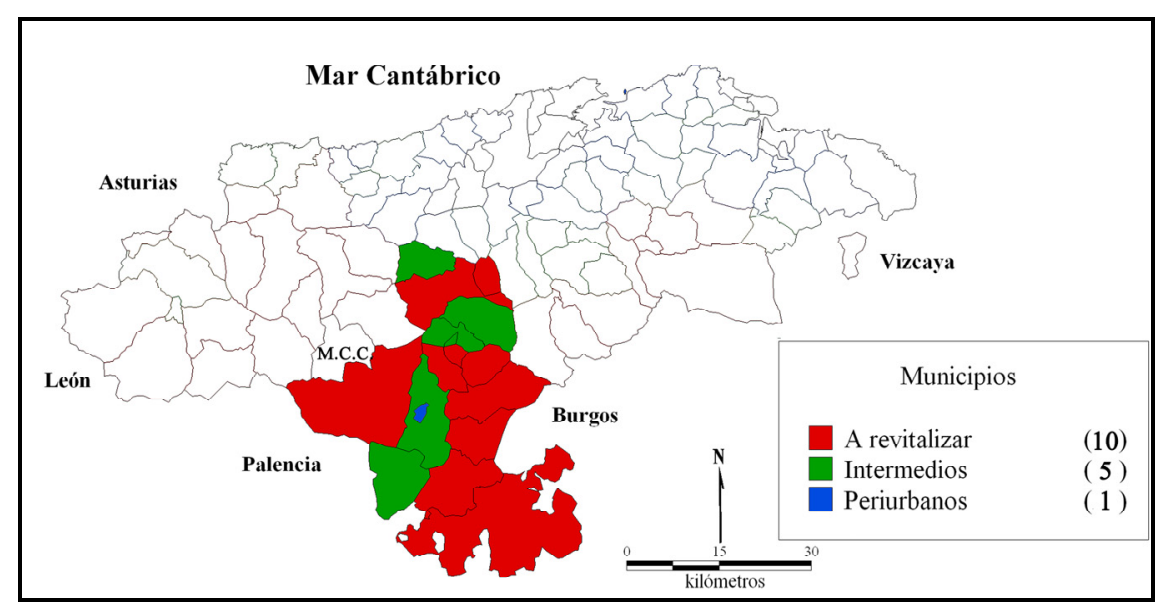

No obstante, la zona delimitada sí constituye un ámbito territorial con una gran cantidad de denominadores comunes. El primero, y más destacable de ellos, el hecho de formar parte de uno de los ejes territoriales funcionales mejor definidos de toda Cantabria, el conocido con el nombre de "corredor del Besaya", que se alarga entre los núcleos industriales de Los Corrales de Buelna, al norte, y Reinosa, al sur, las entidades que constituyen los centros de referencia del territorio comprendido en esta zona.

Sin embargo, el papel territorial desempeñado desde hace tiempo por cada uno de esos núcleos ha sido distinto; motivo que justifica el tratamiento diferente que se otorga a cada uno de ellos en esta propuesta de delimitación.

El núcleo principal de Los Corrales de Buelna ha sido y es, sin lugar a dudas, centro de referencia de carácter subregional del territorio del Valle de Iguña, para el que resulta más accesible, no tanto por su proximidad (la distancia a Los Corrales de Buelna es similar a la de Reinosa) cuanto por el hecho de que para llegar a Reinosa había que ascender a la culminación de la Cordillera por la carretera N-611 a través de la hoces del Besaya mientras que para llegar a Los Corrales el trayecto discurre por la misma carretera por un terreno más llano. Las diferencias de accesibilidad a uno y otro núcleo eran significativas por sus dificultades, sobre todo en la estación invernal. En la actualidad el desplazamiento puede hacerse a través de la autovía A-67, recientemente completada, en condi- 
ciones muy similares por lo que las diferencias en cuanto a la accesibilidad tenderán a atenuarse $\mathrm{o}$, incluso, a desaparecer.

Por otra parte, Los Corrales de Buelna no sólo funciona ya como cabecera de los municipios situados en el sector medio del valle del Besaya, en los Valles de Buelna e Iguña, sino que, en la actualidad, está quedando cada vez más vinculado al área periurbana de Torrelavega, integrado en el pequeño continuum rururbano que se está configurando entre ambos núcleos a través del nexo de unión de Cartes. Esta nueva situación ha empezado a diluir su carácter tradicional de cabecera comarcal, entre otras razones porque las recientes mejoras de la accesibilidad facilitan que esa función la desempeñe con mayor eficiencia la propia ciudad de Torrelavega, que ofrece mejores servicios en cantidad y calidad.

Por todo lo cual no resulta imprescindible integrar el municipio de Los Corrales de Buelna en esta zona a revitalizar puesto que, además, su dinámica socioeconómica y territorial apenas tiene hoy dependencia del espacio rural de su entorno. Si bien es cierto que, por el contrario, el dinamismo económico de su núcleo principal, y en particular la oferta de trabajo que pueden generar las actividades productivas localizadas allí, sí podrían estimular el desarrollo del espacio rural próximo al incrementar el volumen de empleos no agrarios disponibles, complementarios o exclusivos, para los habitantes de los municipios rurales del Valle de Iguña y de los más septentrionales de Campoo. En las condiciones actuales es factible aumentar la movilidad laboral diaria en buenas condiciones y con tiempos de desplazamiento inferiores a 30 minutos.

Es bastante diferente el caso de Reinosa, cabecera comarcal indiscutible del área septentrional de la comarca tradicional de Campoo. Por razones históricas y recientes, el núcleo urbano reinosano ha ejercido funciones como centro de referencia para un amplio conjunto territorial que comprende, además de los municipios campurrianos propiamente dichos (Campoo de Enmedio, Campoo de Yuso y Hermandad de Campoo de Suso), los valles de la vertiente meridional (Valdeolea, Valdeprado del Río y Valderredible).

Desde finales del siglo XIX y a lo largo de todo el siglo XX, la ciudad de Reinosa ha funcionado como centro de la cuenca de empleo constituida por un extenso ámbito territorial que ha abastecido de mano de obra a las empresas industriales establecidas en la ciudad. Esta condición ha tenido consecuencias ambivalentes puesto que, si bien la industria reinosana ha proporcionado empleo a un importante volumen de trabajadores de la comarca, también es cierto que ha contribuido en gran medida al vaciamiento poblacional del espacio rural que constituye su área de influencia. Reinosa ha ejercido en su comarca el mismo papel que muchas ciudades de mayores dimensiones al atraer hacia sí a 
buena parte de la inmigración procedente del medio rural próximo. Esa función desempeñada en el pasado inmediato casi ha desaparecido a partir de la última década del siglo XX, tras el brutal impacto de la crisis y la posterior reconversión industrial en esta comarca.

En la actualidad Reinosa sigue realizando intensas funciones de articulación socioeconómica de este territorio, pero de una forma completamente diferente. La actividad productiva industrial, muy mermada, ha pasado a un segundo plano mientras que las actividades del sector servicios han adquirido un gran protagonismo. La oferta de servicios y equipamientos públicos y privados de la ciudad es cada vez mayor y, por otra parte, también han mejorado mucho las condiciones de accesibilidad y conectividad desde un área cada vez más amplia. En consecuencia, la funcionalidad de la ciudad como centro de servicios subregional se ha incrementado y es la que hoy ejerce de forma prioritaria sobre un territorio cada vez más extenso, que abarca todos los municipios de Campoo y del alto Besaya e, incluso, desborda hacia el norte de la provincia de Palencia y del noroeste de la de Burgos.

Sin la presencia de Reinosa difícilmente podría entenderse en la actualidad el funcionamiento de este ámbito territorial con el que mantiene numerosas ligaduras en una doble dirección. Por un lado, la dinámica de la ciudad es estrechamente dependiente de la de su área rural de influencia cuyos habitantes, junto a los de la propia ciudad, son los consumidores y usuarios potenciales de sus servicios públicos y privados, a la vez que abastecedores de la mano de obra necesaria para atender a la demanda de trabajadores de las actividades urbanas. Pero, al mismo tiempo, la ciudad y su actividad, productiva y de servicios, debería ser un importante agente de articulación territorial y motor de dinamización del espacio rural de su entorno, caracterizado hoy por una dramática situación de atonía demográfica y socioeconómica.

Los argumentos anteriores justifican y aconsejan la inclusión excepcional del municipio de Reinosa, pese a su carácter urbano, en la zona a revitalizar. Por otra parte, su inclusión no puede producir demasiadas distorsiones en la aplicación de la Ley en la zona siempre y cuando se excluya el núcleo urbano propiamente dicho a efecto de las medidas concretas de desarrollo rural. La razón fundamental es que se trata de un término de diminutas dimensiones en superficie $\left(4,12 \mathrm{~km}^{2}\right)$ y prácticamente coincidente con el núcleo urbano, que desborda, incluso, los límites municipales en alguno de los núcleos (Matamorosa) del municipio de Campoo de Enmedio.

Ciñéndose a los argumentos anteriores, la zona a revitalizar propuesta como "Montaña Central" queda formada por 16 términos municipales que suman una extensión de 1.265,48 $\mathrm{km}^{2}$. El volumen de población que en ellos reside en 
2008 es 25.583 habitantes, pero, desde esta perspectiva, es obligado destacar que la población de Reinosa, 10.208 personas, representa el contingente demográfico fundamental $(39,90 \%$ de la población total).

El resto de los municipios son de pequeño tamaño poblacional. Ninguno de ellos llega a 2.000 habitantes e incluso alguno no alcanza los 100, como es el caso de Pesquera, o apenas los supera, como ocurre en el de San Miguel de Aguayo. La única salvedad en este contexto es el municipio de Campoo de Enmedio que tiene casi 4.000 habitantes; pero se trata de una situación excepcional derivada del hecho de que algunos de sus núcleos (Matamorosa, Nestares, Bolmir, Requejo) son, en realidad, barrios soldados al núcleo de Reinosa como consecuencia de las exiguas dimensiones territoriales de aquel municipio.

Los contrastes en la distribución territorial de la población en términos absolutos se reproducen, como es lógico, en la intensidad de ocupación medida en términos relativos a través de la densidad de población.

Figura 6. Distribución de la población de la "Montaña Central" de Cantabria.

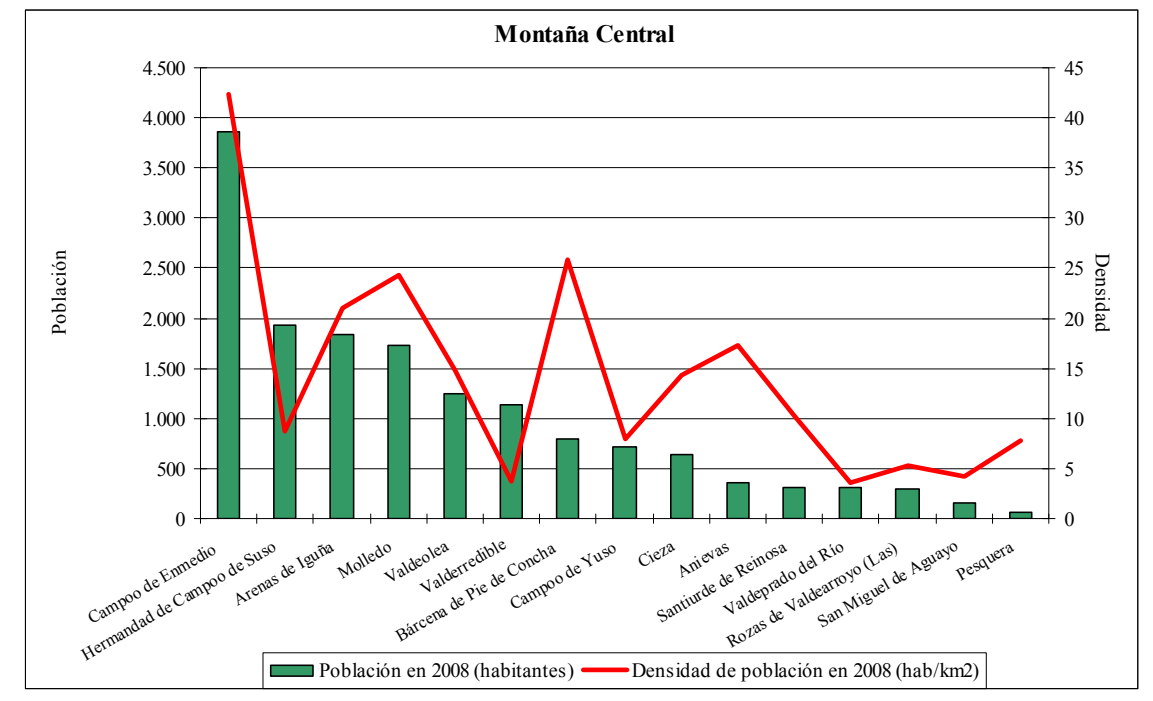

En este aspecto es obligado analizar por separado los datos considerando el municipio de Reinosa y excluyéndolo ya que este municipio alcanza una densidad de $2.477,67 \mathrm{hab} / \mathrm{km}^{2}$, un valor plenamente urbano. De la primera forma, la densidad de población media de la zona son $20,22 \mathrm{hab} / \mathrm{km}^{2}$, de la segunda el valor medio, más representativo, se reduce en ocho puntos porcentuales hasta $12,19 \%$. Aún así, la realidad es bastante más desigual ya que en la zona coexisten términos municipales que no llegan a tener $5 \mathrm{hab} / \mathrm{km}^{2}$ (Valdeprado del Río, 
Valderredible y San Miguel de Aguayo), o apenas los rebasan (Las Rozas de Valdearroyo), con otros que superan los $20 \mathrm{hab} / \mathrm{km}^{2}$, sobre todo los situados en el Valle de Iguña (Bárcena de Pie de Concha, Molledo, Arenas de Iguña), además de Campoo de Enmedio (42,41 hab/ $\mathrm{km}^{2}$ ).

La proporción de población dispersa es también muy elevada en esta zona. Salvo Reinosa, donde la población se concentra en un solo núcleo, en la mayoría de los demás municipios los porcentajes que reflejan la población que vive en núcleos diferentes del principal exceden ampliamente el 50\%; en cuatro municipios (Hermandad de Campoo de Suso, Valderredible, Campoo de Yuso y Valdeprado del Río) se alcanzan los mayores índices con más de las tres cuartas partes de su población habitando en núcleos distintos, casi siempre pequeñas aldeas con un número minúsculo de habitantes.

Los índices de dispersión son sensiblemente más bajos en aquellos términos municipales donde existe algún núcleo con mayores ventajas de situación y de mayores dimensiones. Es el caso de Bárcena de Pie de Concha $(22,87 \%)$ o Valdeolea $(24,35 \%)$ a causa de la preeminencia del núcleo ferroviario-industrial de Mataporquera.

El origen de esta forma de distribución y de ocupación del territorio se encuentra en el modelo disperso de poblamiento tradicional pero reforzado por los procesos recientes de despoblación, que han reducido a mínimos históricos el tamaño demográfico de la multitud de aldeas y barrios, al tiempo que contribuía a aumentar el de los pueblos con mayor centralidad.

La zona rural analizada perdió más del $38 \%$ de su población en el último tercio del siglo XX (35,90\% si se contabiliza Reinosa). Lo que resulta más revelador, pese a que no sea sorprendente, es que también la capital campurriana haya visto menguar su población cuando todos los espacios urbanos y periurbanos de la región tenían importantes aumentos demográficos. Aunque menos que los otros municipios, Reinosa también perdió población, $-1,56 \%$ entre 1970 y 2001 , mientras que había tenido un crecimiento espectacular en las décadas anteriores. No obstante, también es obligado destacar que, en el mismo plazo de tiempo, el municipio que está sirviendo para descongestionar a la capital, Campoo de Enmedio, ha ganado habitantes, $1,05 \%$.

La causa se encuentra en el brutal impacto que aquí tuvo la crisis industrial, y la posterior reconversión, a partir de la década de los años 80 . La ciudad llegó a censar 13.172 habitantes en 1981 y perdió el $18,81 \%$ entre esa fecha y 2001 , de forma que a principios del siglo XXI tenía 3.000 habitantes menos que treinta años antes. Además, el declive demográfico, aunque más lento, ha continuado hasta la actualidad. 
De todas formas, los municipios más netamente rurales de la zona han experimentado durante este tiempo una sangría humana mucho mayor. Algunos han perdido bastante más de la mitad de su población, en particular los valles campurrianos meridionales (Valdeprado del Río -67,53\%, Valdeolea -60,03\%, Valderredible -56,62\%) pero también algunos otros (Pesquera -50,29\%, Las Rozas de Valdearroyo -46,67\%, Santiurde de Reinosa -45,55\%). Frente a este largo y profundo proceso de despoblación, los municipios iguñeses han resultado algo menos perjudicados ya que en ellos el retroceso demográfico en las últimas tres décadas del siglo XX se mantiene en valores comprendidos entre $-30 \%$ y $-40 \%$, con algunas excepciones significativas (Bárcena de Pie de Concha $-16,90 \%)$. A esta situación no parece ser ajeno el mantenimiento de la capacidad de empleo en actividades no agrarias en áreas próximas, como Torrelavega o Los Corrales de Buelna.

Al igual que en el caso de la "Montaña Occidental", lo más significativo y grave es que el proceso de declive poblacional no tiende a remitir: de 1999 a 2008 la zona ha vuelto a perder otro $8 \%$ de su población y el retroceso ha sido generalizado ya que está afectando incluso a municipios del Valle de Iguña, que antes sufrieron menos. Así, por ejemplo, el de Bárcena de Pie de Concha ha perdido en nueve años el mismo porcentaje de población que en los treinta anteriores.

Uno de los municipios con mayor descenso ha sido Reinosa (-11,37\%), lo que parece indicar que la ansiada recuperación está lejos de conseguirse y que Reinosa está sufriendo ahora el efecto boomerang consiguiente al previo vaciamiento humano y productivo de su comarca. Este hecho avala la necesidad de incluir el municipio como espacio a revitalizar, pese a que los indicadores aplicados obliguen a clasificarlo como urbano.

Algunos municipios rurales están teniendo un quebranto poblacional aún mayor. Es llamativo el hecho de que Pesquera haya vuelto a ver disminuir su ya escasa población en otro $27 \%$ o Valdeolea en algo más de $18 \%$. Incluso Campoo de Enmedio ha sufrido un leve retroceso demográfico en el primer decenio del siglo actual.

La mermada población de la zona, además, está sensiblemente envejecida. El índice de envejecimiento alcanza un valor superior a 30\%, con independencia de que se incluya la población de Reinosa, algo más joven (23,92\%). En términos generales, está algo menos envejecida la población del Valle de Iguña $(28,85 \%)$ que la de los municipios campurrianos en alguno de los cuales (Valdeprado del Río) más del $40 \%$ de sus habitantes supera los 65 años, o se acerca mucho a ese valor (Pesquera, Santiurde de Reinosa, Valdeolea). 
La ocupación principal de esa población envejecida es la actividad agropecuaria, a la que se dedica en torno a una tercera parte de sus habitantes, pero con elocuentes diferencias entre unos y otros municipios.

La agraria es casi la única actividad productiva en algunos municipios (San Miguel de Aguayo, 74,07\%, Anievas, 61,11\%) en tanto que en Reinosa la tasa apenas rebasa el 1\% y en Campoo de Enmedio sólo alcanza un 8,65\%. La de la mayoría de los términos municipales se encuentra en una horquilla que va de $20 \%$ a $40 \%$ siendo los valores, en general, más bajos en los del Valle de Iguña y más altos en Campoo.

A diferencia de la "Montaña Occidental", la mayor parte de la zona está bien conectada con los mayores centros de servicios de carácter regional que pueden servir de referencia a sus habitantes. La ciudad mayor de 30.000 habitantes más próxima es, en este caso, Torrelavega con la que la mayor parte de este territorio queda unida a través del ancestral eje de comunicaciones que constituye el corredor del Besaya, surcado por el ferrocarril, la carretera N-611 y, desde hace poco, la vía rápida $\mathrm{A}-67$.

Puesto que casi todos los municipios de la zona se ubican a ambos lados de este eje, las distancias hasta Torrelavega, medidas en tiempo, no son grandes y, además, se han acortado bastante tras la puesta en funcionamiento de la A-67 que ha mejorado mucho la accesibilidad. Es esto lo que explica que la distancia media de la zona sea 36 minutos, un valor bastante coincidente con el particular de la mayoría de los municipios. Sólo algunas áreas del extenso municipio de Valderredible, entre ellas su capital, están algo más alejadas puesto que el desplazamiento tiene todavía una duración superior a los 60 minutos.

Los niveles de renta también son, comparativamente, algo mejores que los de la "Montaña Occidental", pero quedan aún bastante lejos de la media regional a la que únicamente se aproxima la renta per cápita del municipio de Reinosa. Pero, incluso contabilizándola, la reta per cápita media de la zona apenas superaba los 9.000 euros en 2004 (8.969 € si no se contabiliza a Reinosa en el promedio). La de un municipio (Las Rozas de Valdearroyo) no llegaba a 7.000 euros y en otros dos (Valderredible y San Miguel de Aguayo) no se alcanzan los 8.000 euros. Por el contrario, además de los de Reinosa, los habitantes de Arenas de Iguña, Bárcena de Pie de Concha, Campoo de Enmedio, Campoo de Yuso, Cieza, Hermandad de Campoo de Suso y Valdeolea disfrutan de rentas superiores a la media de la zona.

Lo mismo que se afirmó en el caso de la "Montaña Occidental", los indicadores utilizados no dejan lugar a dudas sobre la perentoria necesidad de actuar lo 
más pronto posible para dinamizar la economía de este territorio e intentar fijar la población en él, única vía para mantenerlo vivo.

\section{II.3. La "Montaña Oriental" (Valles del Pas-Pisueña, Miera y Asón- Agüera)}

La zona a revitalizar que a la que se ha dado el nombre de "Montaña Oriental" está integrada por las áreas de las cabeceras y los sectores medios de los valles de los ríos Pas, Miera y Asón, y la práctica totalidad de las cuencas de los cursos del Agüera y del Pisueña, afluente el segundo del Pas en su tramo medio. Un ámbito geográfico denominado en otras ocasiones como "valles orientales" y que coincide casi plenamente con el sector cántabro del territorio histórico de la Jurisdicción de los Montes de Pas, el área pasiega y su entorno "pasieguizado".

La zona esta compuesta por 17 municipios que ocupan una superficie de algo menos de $1.000 \mathrm{~km}^{2}$ en la que habitan en 2008 poco más de 19.200 personas.

Figura 7. Delimitación y localización de la "Montaña Oriental" de Cantabria.

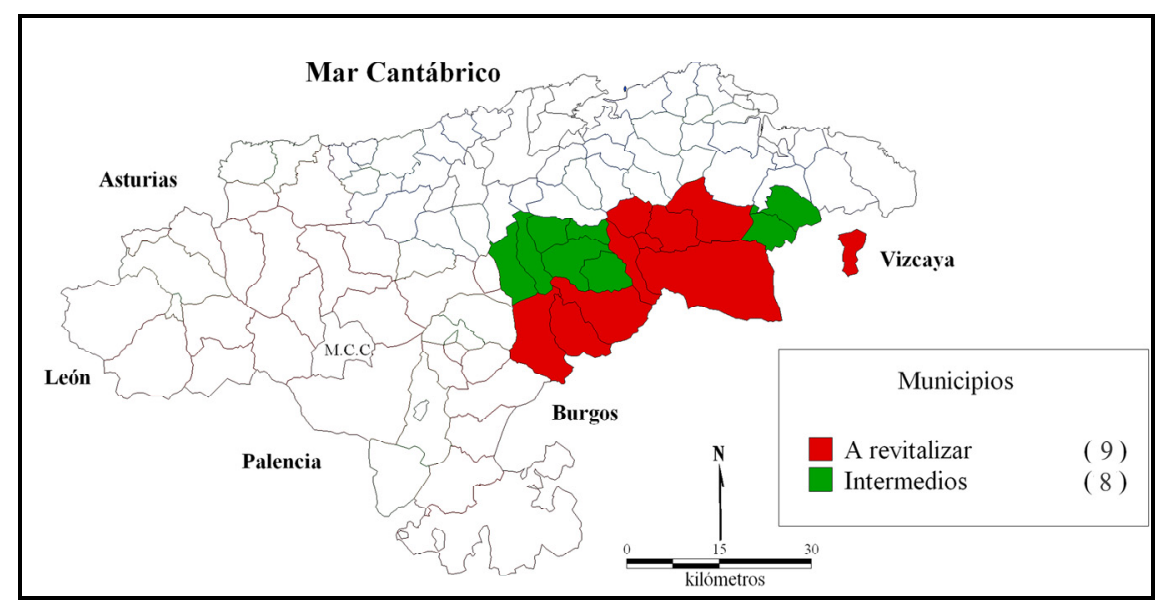

La mayor parte de esos términos municipales (9) han resultado clasificados como a revitalizar y otros 8 como intermedios, la mayoría situados a menor altitud en el valle del Pisueña (Saro, Selaya, Villacarriedo y Villafufre) y en los tramos medios de los respectivos valles del Pas (Corvera y Santiurde de Toranzo) y del Asón (Ramales de la Victoria y Rasines). La pertenencia a la categoría intermedia de tres de estos municipios no es ajena a su carácter de núcleos con centralidad comarcal; centralidad administrativa en el caso de Villacarriedo y de servicios públicos y privados en los de Selaya y Ramales de la Victoria para el área del Pas-Pisueña en los dos primeros y en la del Asón en el tercero. No debe 
olvidarse, además, que los núcleos de población principales de los términos municipales de Villacarriedo y Selaya han empezado a formar un minúsculo continuum urbano, lo que refuerza la centralidad conjunta de ambos en su comarca.

De lo expuesto hasta aquí cabe inferir que la zona analizada está formada por dos subcomarcas funcionales, la del alto Pas-Pisueña nucleada por Villacarriedo-Selaya y la del alto Asón-Soba articulada a partir de Ramales de la Victoria. A ellas cabe añadir otras dos: una tercera constituida por el valle medio del Pas, cuyo centro secundario de referencia es Alceda-Ontaneda y la cuarta formada por el alto valle del Miera cuyo centro de servicios de proximidad se encuentra en Liérganes, capital del municipio del mismo nombre, que está situado fuera de la zona delimitada pero colindando con ella por el norte.

Aunque, por razones de coherencia en la aplicación de los criterios básicos, no se hayan incluido en esta propuesta de delimitación, no sería desatinado integrar en esta zona los municipios de Santa María de Cayón, Penagos y Liérganes. Los tres mantienen todavía bastantes vínculos funcionales con la comarca pasiega, si bien presentan rasgos de urbanización y periurbanización que les identifican en la actualidad mucho más con los municipios situados más al norte, con los que configuran la zona periurbana denominada "Marina Oriental".

En los demás aspectos considerados la zona presenta un notable nivel de homogeneidad. Es así por lo que se refiere, en general, a las condiciones topográficas, las propias de un área de montaña con altitudes medias pero, sobre todo, con grandes diferencias de altitud entre lugares próximos, lo que confiere un predominio absoluto a las tierras en pendiente. La pendiente media de la zona es elevada, un valor que resulta de promediar las condiciones de mayor pendiente de los municipios situados en las cabeceras de los ríos Pas, Miera y Asón con los valores algo más bajos que arrojan los municipios situados en el valle del Pisueña o en los tramos medios de los valles de los otros cursos fluviales que, por lo general, presentan valores más bajos.

En el mismo sentido hay que entender que la organización morfológica del relieve, fragmentado en valles separados por interfluvios que dificultan la conectividad entre sí, es la que explica en gran medida la división interna de la zona en cuatro subcomarcas con funcionalidad parcialmente diferenciada, tanto en el pasado como en el presente.

Mayores discordancias se producen en la distribución de la población sobre el territorio, aunque los contrastes son menores que en las otras zonas a revitalizar consideradas. 
Aunque algunos términos municipales presentan volúmenes de población muy reducidos (Valle de Villaverde, Miera, San Roque de Riomiera, San Pedro del Romeral), ninguno llega a los extremos de exigüidad de algunos de los mencionados en la "Montaña Occidental" y en la "Montaña Central" ya que el más pequeño, Valle de Villaverde, se acerca a los 400 habitantes.

Por otro lado, nueve municipios sobrepasan los 1.000 habitantes, un tamaño aceptable en el contexto regional, y tres de ellos (Selaya, Corvera de Toranzo y Ramales), los tres que ejercen funciones centrales en sus respectivos valles e, incluso, en tramos particulares de valle, superan los 2.000 .

Las diferencias en tamaño territorial entre unos y otros términos no son muy acusadas si exceptuamos los casos de Saro, por su pequeñez $\left(17,8 \mathrm{~km}^{2}\right)$ y de Luena $\left(90,5 \mathrm{~km}^{2}\right)$, Ruesga $\left(87,9 \mathrm{~km}^{2}\right)$, y sobre todo, Soba $\left(214,2 \mathrm{~km}^{2}\right)$ por sus mayores dimensiones. Esa desigualdad puede explicar parcialmente los contrastes en cuanto a la densidad de población, pero este valor depende en mayor medida del volumen de población en términos absolutos.

Figura 8. Distribución de la población de la "Montaña Oriental" de Cantabria.

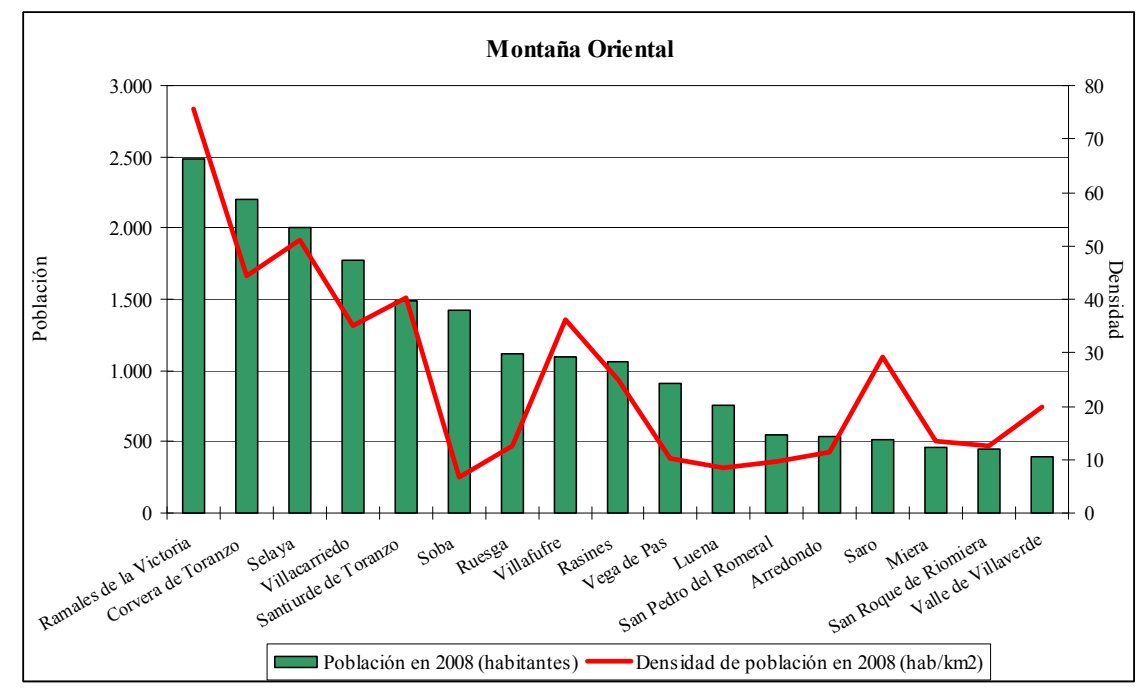

La densidad media de población de la zona es modesta, $19,73 \mathrm{hab} / \mathrm{km}^{2}$, pero no extremadamente baja. La causa hay que atribuirla a la presencia de algunos municipios con valores relativamente elevados para el medio rural, en particular aquellos en los que se encuentran las cabeceras comarcales: Ramales de la Victoria con $75,49 \mathrm{hab} / \mathrm{km}^{2}$, Selaya con $50,98 \mathrm{hab} / \mathrm{km}^{2}$ y Corvera de Toranzo con $44,50 \mathrm{hab} / \mathrm{km}^{2}$. Junto a ellos, un número pequeño de municipios no alcanzan los $10 \mathrm{hab} / \mathrm{km}^{2}$ : Luena $\left(8,37 \mathrm{hab} / \mathrm{km}^{2}\right)$, San Pedro del Romeral $\left(9,54 \mathrm{hab} / \mathrm{km}^{2}\right)$, So- 
ba $\left(6,66 \mathrm{hab} / \mathrm{km}^{2}\right)$; el emplazamiento de los tres municipios en las zonas más elevadas y menos accesibles de las áreas de cabecera, casi en la divisoria montañosa, es el denominador común de localización de los municipios más despoblados de la zona. Estos seis términos municipales constituyen las excepciones más relevantes, por ambos extremos, al patrón de densidad de la mayoría de los de la zona, que se mantienen en valores bajos pero relativamente moderados con respecto a los promedios dominantes en el conjunto del espacio rural regional.

También aquí, como en las otras dos zonas a revitalizar, el déficit poblacional es consecuencia de la evolución reciente de la población. El conjunto del área perdió casi el $30 \%$ de sus habitantes aunque no todos los municipios contribuyeron en idéntica medida la mengua de población. En algunos casos, como los del valle del Miera, las pérdidas superaron el $50 \%$ mientras que en otros (Corvera y Santiurde de Toranzo, Rasines y Villafufre) apenas rozaron el 20\%. De esta situación apenas se salvaron las principales cabeceras comarcales: Ramales de la Victoria con una mínima ganancia $(1,31 \%)$ y Selaya con una pequeña merma $(-3,52 \%)$.

Igualmente, el cambio de siglo no ha representado en el territorio pasiego una modificación significativa de la dinámica regresiva ya que el conjunto comarcal sigue perdiendo población y, en términos generales, los mayores retrocesos siguen correspondiendo a los que sufrieron un declive más intenso en la etapa anterior, lo que consolida la tendencia a la despoblación.

Es preciso resaltar, no obstante, que en los años transcurridos de la presente centuria, algunas áreas de esta zona han empezado a ganar población. Así ocurre, de manera más destacada, en el caso de los municipios situados en el curso medio del Asón-Agüera, Ramales de la Victoria, Rasines y Valle de Villaverde $(10,47 \%, 10,73 \%$ y $5,12 \%$ respectivamente), tal vez como consecuencia de la funcionalidad recién adquirida de espacios residenciales de vivienda secundaria, incluso principal en algunos casos, de población procedente de áreas urbanas próximas, cántabras y vascas. En menor medida, el crecimiento de población o, en su defecto, el estancamiento de la misma, también se está dejando sentir en los municipios situados a menor altitud y mejor comunicados de los valles del Pas y el Pisueña; como sucede en Corvera de Toranzo (4,76\%), Villacarriedo $(0,62 \%)$ y Selaya $(-0,05 \%)$.

La dinámica poblacional actual parece estar reforzando la discriminación territorial que ya se había esbozado en el período anterior.

No obstante, la condición de desventaja fundamental en cuanto a las formas de ocupación del territorio por parte de la población de esta zona no proviene 
sólo de la inferioridad de las densidades, sino de la forma de poblamiento definida por unas tasas de dispersión imposibles de cuantificar con los datos censales.

La tasa de dispersión media es muy alta: casi el 63\% de la población habita en núcleos diferentes del principal en cada término municipal, pero este dato tiene un significado meramente estadístico por cuanto encubre tasas de dispersión mucho mayores, como las de Soba (92,08\%), Luena (87,60\%), Corvera de Toranzo, Rasines, San Pedro del Romeral, Santiurde de Toranzo y Villacarriedo (todos ellos por encima de 70\%). Por el contrario, los municipios donde se ubican los núcleos con mayor centralidad comarcal, tienen tasas de dispersión mucho menores: Ramales de la Victoria $16,07 \%$ y Selaya $23,36 \%$.

La realidad de la dispersión del poblamiento, sin embargo, como ya se manifestó en otras ocasiones, es muy superior puesto que el patrón de ocupación del territorio se acerca a la diseminación absoluta en algunos barrios, que son meras entidades carentes de núcleo, agrupaciones territoriales de viviendas esparcidas por los fondos y las laderas más tendidas de los valles.

El modelo de poblamiento es una herencia de las formas de aprovechamiento agropecuario tradicional, expresado en el "modo de vida pasiego" y materializado en un legado patrimonial y paisajístico de extraordinario valor. Pero en la actualidad las formas de producción agraria y los modos de de vida rurales han cambiado, y la dispersión extrema es más una desventaja agravada por otros rasgos que caracterizan a la población comarcal, como los altos niveles de envejecimiento, pese a que son menores que los reseñados para las otras dos zonas a revitalizar montañosas.

En el año 2008 algo más de la cuarta parte de los habitantes, el 26,47\%, tienen más de 65 años, un valor medio que, en esta ocasión, resulta bastante representativo. La tasa es más baja, como era de esperar, en los municipios más dinámicos cuyos núcleos centrales funcionan como centros de referencia a escala comarcal y subcomarcal, Selaya $(19,92 \%)$, Corvera de Toranzo $(22,34 \%)$ y Ramales de la Victoria $(23,46 \%)$. Aunque algunos municipios tienen algo más del $30 \%$ de población vieja, la mayoría se mantienen en valores muy próximos a la media.

La sorprendente situación de menor envejecimiento relativo que presenta esta zona, debería contemplarse y ser aprovechada como una oportunidad, poco frecuente en las comarcas de montaña, a la hora de implementar medidas de desarrollo rural.

A ello puede contribuir otra nueva ventaja de situación, la atenuación del aislamiento geográfico en que vivió tradicionalmente la población de los valles 
orientales. La reciente mejora de las infraestructuras y los medios de comunicación se manifiesta en la proximidad en tiempo de la mayor parte del territorio de esta zona, con la salvedad de algunos rincones, a los centros de servicios regionales y subregionales más próximos, Santander y Castro Urdiales en este caso.

El tiempo de desplazamiento medio a alguna de estas ciudades es de 38 minutos y son contados los municipios cuyos habitantes tienen que emplear mayor tiempo en el desplazamiento: sólo desde los lugares más apartados de Soba y San Pedro del Romeral es necesario invertir aproximadamente una hora en el viaje.

La actividad agraria tiene aquí un peso mayor que en otras zonas rurales cántabras. Casi la mitad de la población ocupada, 46,24\%) lo está en empleos agrarios. Este valor medio es ampliamente rebasado en algunos municipios donde las actividades productivas del sector primario rozan la exclusividad. Tal es el caso del Valle de Soba, donde los empleos agrarios representan el 71,29\% del total, de Saro $(67,71 \%)$ o de Miera (62,12\%). Por el contrario, en los municipios-cabeceras los activos agrarios tienen una presencia menor: "sólo" representan el 7,98\% en el de Ramales de la Victoria, el 12,31\% en Corvera de Toranzo y el $27,55 \%$ en Selaya. En el resto de los términos municipales los valores se mantienen, por término general, en torno a la mitad de la población ocupada.

La renta per cápita media es un indicador que refleja con bastante precisión en esta ocasión la combinación de rasgos del medio rural que acabamos de exponer. Como en las otras zonas a revitalizar, el promedio comarcal, $8.465 €$ en 2004 , dista mucho de los $12.153 €$ de la media regional en la misma fecha. Pero no hay aquí ningún municipio cuyas rentas medias estén por debajo de $7.000 €$, aunque ese valor apenas se sobrepase en San Roque de Riomiera. En seis términos municipales las rentas per cápita medias se mantienen entre 7.000 y 8.000 $€$, en otros cinco se sitúan entre 8.000 y $9.000 €$ y en otros seis se supera esa cantidad. Como era de suponer, entre estos últimos se encuentran los municipios con mayor centralidad en uno de los cuales, Ramales de la Victoria, sus habitantes disponen de una renta per cápita media que excede, aunque por poco, $\operatorname{los} 10.000 €$.

El cúmulo de rasgos ventajosos e inconvenientes que define en conjunto a esta zona aconseja la aplicación de medidas de desarrollo con bastantes probabilidades de estar a tiempo todavía de obtener resultados eficaces con relativa facilidad.

\section{BIBLIOGRAFÍA}

ANUARIO de Estadística Agraria Pesquera de Cantabria (2005, 2006, 2007, 2008). San- 
tander, Gobierno de Cantabria/Consejería de Ganadería, Agricultura y Pesca.

Corbera Millán, M. (Ed.) (1999): Cambios en los Espacios Rurales Cantábricos tras la integración de España en la UE, Santander, Universidad de Cantabria.

DELGADO VIÑAS, C. (1997): «Crisis y reconversión en espacios rurales de montaña en Cantabria» Ería, n $44,335-357$.

DELGADO VIÑAS, C. (2000): «Changements récents des systèmes agraires dans les espaces ruraux de la Cantabrie (Espagne)» Les nouveaux espaces ruraux de l'Europe Atlantique , 48-61. Poitiers, Université de Poitiers.

Delgado Viñas, C. (2003): Los Montes de Pas. Realidad presente y expectativas de futuro. Santander, Universidad de Cantabria.

Delgado ViÑAS, C. (Ed.) (2006a): La Montaña Cantábrica, una montaña viva. Santander, Universidad de Cantabria.

DELGADO VIÑAS, C. (2006b): «Continuidad y renovación de la actividad ganadera en la Montaña Cantábrica» en Delgado ViÑAS, C. (Ed.): La Montaña Cantábrica, una montaña viva. Santander, Universidad de Cantabria, 97-116.

DELGADO VIÑAS, C. (2006c): «Ordenación del territorio y desarrollo sostenible en áreas de montaña: diagnóstico y propuestas para la integración productiva y territorial de los Montes del Pas (Cantabria)» en Boletín de la Asociación de Geógrafos Españoles, $\mathrm{n}^{\mathrm{o}}$ 42, 53-70.

DELGADO VIÑAS, C. (2010): «Dinámicas socioterritoriales recientes de los espacios rurales de Cantabria» en Actas del XV Coloquio de Geografia Rural: Territorio, Paisaje y Patrimonio Rural. Cáceres, AGE/Universidad de Extremadura.

Delgado VIÑAS, C. y GIL DE ARRIBA, C. (2008): «Dinámica y desarrollo territorial de la Montaña Cantábrica: el ejemplo de las comarcas cántabras de Campoo y Cabuérniga-Tudanca» en Ería, n ${ }^{\circ}$ 75, 53-76.

Delgado Viñas, C., Gil de Arriba, C., Hortelano Mínguez, L.A. y PlaZA GUTIÉRREZ, J.I. (2003): «Referencias indicativas de los procesos de cambio territorial en un espacio de montaña (Sector Central de la Montaña Cantábrica)» en Geographicalia (Universidad de Zaragoza), n $45,65-88$.

Delgado Viñas, C., Gil de Arriba, C., Hortelano Mínguez, L. A. y Plaza GUTIÉRREZ, J. I. (2004): «La renovación rural en los espacios de montaña. Las comarcas de la vertiente Norte del sector central de la Cordillera Cantábrica» en Investigaciones Geográficas, $\mathrm{n}^{\circ}$ 33, 63-86, http://www.cervantesvirtual.com/servlet/ SirveObras/12471209681243732976735

Delgado, C., Gil, C., HoRTelano, L.A. y PlazA, J.I. (2007): Dinámica territorial y transformación del paisaje en la Montaña Cantábrica. Salamanca. Plaza Universitaria Ediciones.

Delgado, C., Gil, C., Hortelano, L.A. y PlazA, J.I. (2010): La Montaña Cantábrica Oriental. Dinámica socioeconómica, patrimonio ecocultural y desarrollo territorial. Santander, Ed. Estvdio.

GALDÓs URRUTIA, R. (2006): «Cambios y diversidad geodemográfica en las Montañas Cantábricas» en DELGADO VIÑAS, C. (Ed.): La Montaña Cantábrica, una montaña viva. Santander, Universidad de Cantabria, 151-173

GIL DE ARRIBA, C. (2006): «Turismo y segunda residencia en la Montaña Cantábrica: expectativas y riesgos» en DELGADO VIÑAS, C. (Ed.): La Montaña Cantábrica, una montaña viva. Santander, Universidad de Cantabria, 129-150. 
Gobierno de CANTABria (2008): Programa de Desarrollo Rural de Cantabria 20072013. Consejería de Desarrollo Rural, Pesca y Biodiversidad.

ORTEGA VAlCARCEL, J. (1999): «Procesos de cambio en las áreas rurales cantábricas. La evolución de los espacios rurales cantábricos y la integración de España en la Unión Europea» en CORBERA MILlÁN, M. (Ed.) (1999), 237-250.

RED CÁNTABRA DE DeSARRollo RuRAL (2008): Nuestro medio rural "más para los menos". Santander, Gráficas Quinzaños. 